\title{
Complutum
}

ISSN: 1131-6993

\section{Reflexionando sobre la mujer aborigen de Gran Canaria: integrando arqueología y etnohistoria desde una perspectiva de género}

\author{
Jonathan A. Santana Cabrera ${ }^{1}$
}

Recibido: 30 de enero de 2018 / Aceptado: 28 de junio de 2018.

Resumen. Esta contribución tiene el propósito de reflexionar sobre el papel de la mujer en la sociedad aborigen de Gran Canaria. En el texto se consideran una serie de evidencias arqueológicas y etnohistóricas que sugieren que las relaciones sociales de los antiguos canarios estaban sustentadas en un sistema de género asimétrico dominado por los hombres. La división sexual del trabajo, un acceso asimétrico a lo producido, la gestión de las relaciones de parentesco y la capacidad reproductora de las mujeres, así como su papel en el mundo religioso y funerario, son considerados con el objetivo de alcanzar una visión generalista sobre las condiciones de vida de las mujeres prehispánicas.

Palabras clave: Arqueología de Género; Islas Canarias; Prehispánico; Bioarqueología; Etnohistórico.

\section{[en] Reflecting on aboriginal women of Gran Canaria: integrating archaeology and ethnohistory from a gender perspective}

\begin{abstract}
This contribution is intended to consider the role of women in the pre-Hispanic society of Gran Canaria. I consider several archaeological and ethnohistorical evidences that suggest that the social relationships were based on an asymmetric gender system dominated by males. The sexual division of labour, an asymmetric access to what was produced, the control of kinship relationships and the reproductive capacity of women, as well as their role in the religious and funerary spheres, are considered together to reach a wide understanding of the daily-life conditions of the pre-Hispanic women.
\end{abstract}

Key words: Gender Archaeology, Canary Islands, Pre-Hispanic, Bioarchaeology, Ethnohistoric.

Sumario: 1. Una arqueología necesaria. 2. Hombres y mujeres juntos, pero no revueltos. 3. Lo comido por lo servido... 4. El que quiera lapas... 5. Andamana, Arminda y un matrimonio de conveniencia. 6. En su casa el enemigo. 7. Imaginando la abundancia. 8. Madre no hay más que UNA. 9. Así en la vida como en la muerte.

Cómo citar: Santana Cabrera, J.A. (2018): Reflexionando sobre la mujer aborigen de Gran Canaria: integrando arqueología y etnohistoria desde una perspectiva de género. Complutum, 29(1): 207-224.

\section{Eva / del varón fuiste tomada / hueso de sus huesos / carne de su carne / ¿cómo pudiste pecar? / ¿cómo osaste codiciar / los frutos del árbol /del bien y del mal? Eva, Pedro Guerra}

\section{Una arqueología necesaria}

La isla de Gran Canaria fue poblada en el primer milenio de nuestra Era por colonizadores procedentes del norte de África (Maca Meyer et al., 2004; Fregel et al, 2009, 2015; Velasco, 2015; Morales et al., 2017). Esta población, conocida como canarios, desarrolló una economía agropecuaria excedentaria con una impor- tante contribución de los productos procedentes de la explotación marina (Velasco, 1999; Delgado, 2009; Morales et al., 2014). Las evidencias arqueológicas sugieren que Gran Canaria y las otras islas del archipiélago (Fig. 1) quedaron aisladas hasta la llegada de los primeros viajeros europeos en los siglos XIII y XIV, siendo finalmente anexionadas a la Corona de Castilla a finales del siglo XV (Aznar Vallejo, 1983).

\footnotetext{
Marie Skłodowska Curie Fellow. Department of Archaeology. Durham University. South Road, DH1 3LE, Durham. Reino Unido.
} E-mail: jonathan.a.santana-cabrera@durham.ac.uk 


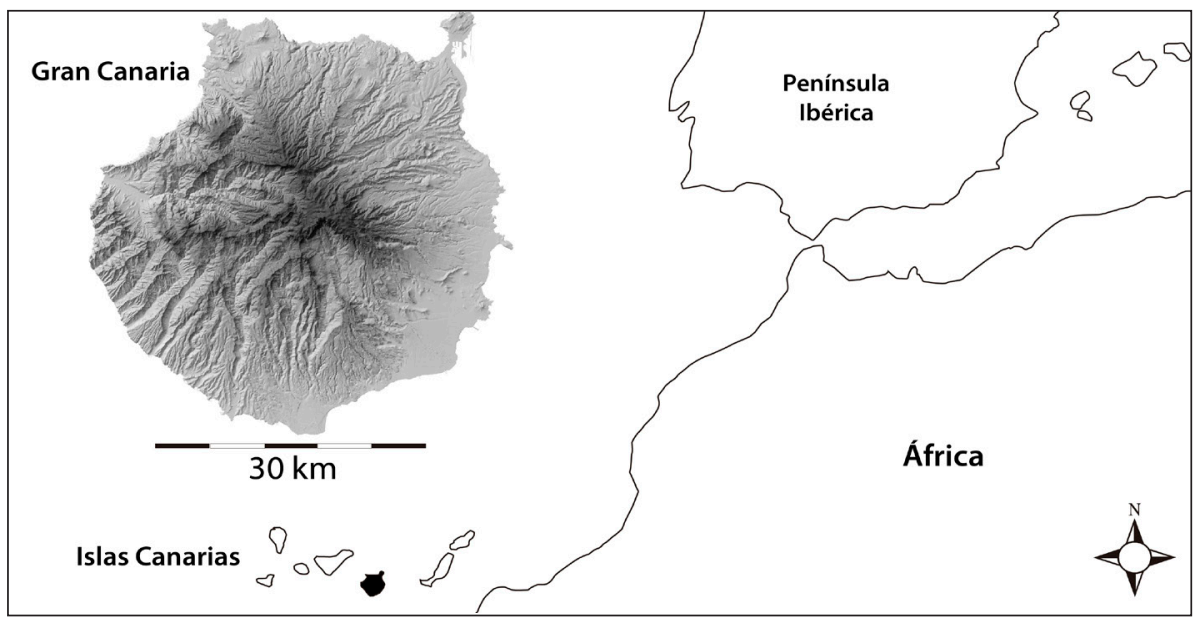

Figura 1. Mapa de la isla de Gran Canaria.

El papel de la mujer aborigen, los roles de género y las relaciones que los atañen son todavía poco conocidos en la Arqueología de Gran Canaria. Son escasos los ejemplos que desde un posicionamiento teórico expreso han intentado explorar las relaciones entre los distintos géneros y los estatus asociados a cada uno de ellos (Pérez Saavedra, 1997; Rodríguez, 2006). Tampoco son muy numerosas las contribuciones que indirectamente han abordado estas cuestiones, si bien han supuesto un avance significativo para mejorar la visibilidad de las mujeres y lo femenino en el registro arqueológico. Un ejemplo son los estudios que desde el ámbito de la Bioarqueología han abordado el estado paleonutricional de los aborígenes (Velasco, 1999; Delgado, 2009), y la división sexual del trabajo (Velasco et al., 2001; Delgado et al., 2002; Santana et al., 2011-2012; 2015). Otras aportaciones han contrastado algunos objetos y procesos de trabajo documentados en los yacimientos arqueológicos con las descripciones que se hacen sobre ellos en las fuentes etnohistóricas, poniendo de manifiesto el destacado impacto que la ideología patriarcal tiene en estos textos, y la escasa atención que se dedica a la mujer y lo femenino (González y Rodríguez, 1998; 2006).

Estas fuentes son un conjunto muy heterogéneo de textos que incluyen relatos de viajeros, crónicas de la conquista de la isla, y documentos administrativos del periodo de contacto y colonización europea (Onrubia, 2003; Baucells, 2004). Describen aspectos muy interesantes de la vida cotidiana de la sociedad aborigen donde, además, detallan cuestiones que atañen a las relaciones de género mencio- nando aspectos como la división sexual del trabajo, los estatus de hombres y mujeres, y los aspectos simbólicos ligados a lo masculino y lo femenino. Estos relatos describen un contexto general a partir del cual se puede investigar la evidencia arqueológica e, incluso, afrontar otras cuestiones que el registro arqueológico no posibilita. Aun así, estas fuentes adolecen de ciertos inconvenientes a la hora de su utilización como recurso histórico. Primero, se trata de una información parcial que en la mayoría de los casos procede de contextos puntuales y que es utilizada para generalizar sobre un aspecto complejo de la sociedad; segundo, son textos que están fuertemente mediatizados por los prejuicios de los escritores, cuyos paradigmas sospechamos derivan de la ideología patriarcal de la época, y que se traduce en una trivialización del papel de las mujeres aborígenes y de un mayor protagonismo de los varones y sus actividades (González y Rodríguez, 1998; 2006; Rodríguez, 2006).

Según estas fuentes, el sistema de género prehispánico se limitaba a los roles masculino y femenino, identificados con los atributos biológicamente específicos que dividen a la especie humana entre machos y hembras (Fig. 2). Esta interpretación se origina desde la visión de unos escritores que consideran los códigos sociales del cristianismo como universales o, al menos, como los más adecuados para describir cualquier sociedad. De tal modo que, lejos de ser concluyente, el sistema de género propuesto en los textos etnohistóricos debe ser considerado con cautela pues, ante todo, constituye un producto generado por los escritores de estas fuentes, y no un reflejo de la realidad que ellos 
describen. Dicha problemática no sólo afecta a este asunto, sino que se extiende a todos los aspectos de la vida de los antiguos canarios que estos documentos abarcan. Tanto es así, que cabría preguntarse hasta qué punto nuestro concepto general sobre esta sociedad es resultado de la visión de estos escritores y no de la realidad histórica concreta de los antiguos canarios.

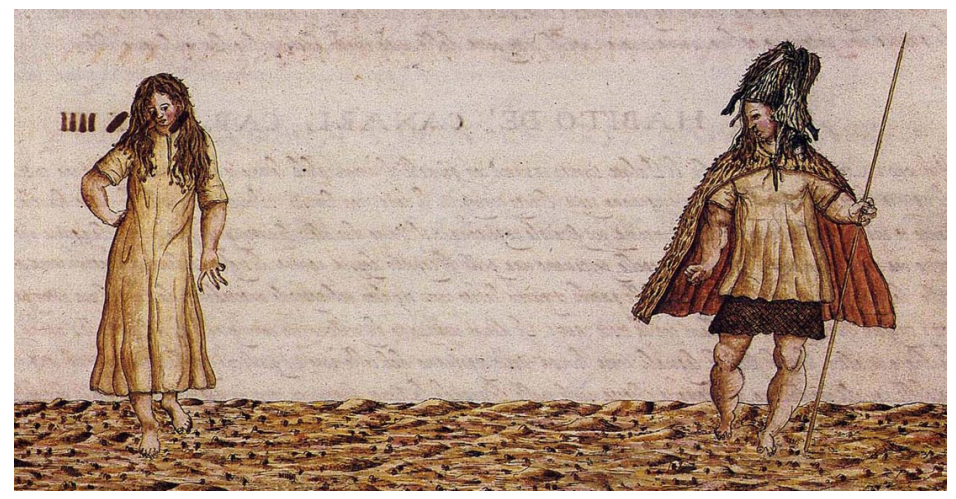

Figura 2. Ilustración de las vestimentas de los antiguos canarios realizada por el ingeniero cremonés Leonardo Torriani ([c. 1592] 1978).

Sin poner en duda la valía de las fuentes etnohistóricas como recurso de investigación histórica, desde nuestro punto de vista los datos más contundentes generados hasta el momento para conocer el pasado de las mujeres aborígenes proceden de las evidencias arqueológicas, en especial de aquellas que atañen a los restos óseos humanos recuperados de los cementerios aborígenes. Los huesos tienen la ventaja fundamental de que pueden ser sexuados a partir del análisis osteoarqueológico, permitiendo desde un primer momento, una división entre hombres y mujeres según el sexo biológico (cuando la conservación del material así lo permite). La problemática subyacente a esta línea de investigación reside en la dificultad de establecer relaciones coherentes entre las evidencias observadas en los huesos, el sexo y los roles de género. De hecho, es más que probable que nunca podamos abordar esta relación en toda su complejidad dada la imposibilidad de rastrear más categorías de género, al menos a partir de las evidencias arqueológicas conocidas hasta el momento.

Los objetos materiales que se encuentran en los yacimientos arqueológicos son también importantes evidencias que, en determinadas circunstancias, pueden asociarse con un sexo y/o género en concreto. Este es el caso de algunos productos que las fuentes etnohistóricas y los marcadores óseos de actividad física relacionan con un sexo específico (Rodríguez, 2006; Delgado, 2009). No obstante, lo cierto es que son escasos los ejemplos donde se pueden generar este tipo de relaciones, dada las distintas problemáticas que subyacen a esta clase de evidencias. Una de ellas consiste en la invisibilidad de los objetos sexuados, es decir, la dificultad para saber qué objetos, estructuras, etc., fueron elaborados, utilizados, o aprovechados por hombres, por mujeres, o por ambos sexos. Otra viene condicionada por la influencia de los prejuicios androcéntricos en nuestros propios planteamientos interpretativos, que nos hacen relacionar directamente, por ejemplo, lo doméstico con lo femenino, reproduciendo nuestras propias concepciones en la realidad arqueológica que estamos abordando.

Este artículo pretende proponer una visión general del papel de las mujeres en la sociedad aborigen de Gran Canaria atendiendo a varias cuestiones que el binomio arqueología y fuentes etnohistóricas nos permite abordar de manera objetivable. Estas materias tratan sobre la división sexual del trabajo, el acceso asimétrico a los alimentos como estrategia social, la violencia ejercida contra las mujeres, la relación de las mujeres y lo femenino con la religión y las estructuras de poder, el control de la reproducción biológica, y las prácticas funerarias. La exposición de estos temas nos ayudará a discutir no sólo sobre las mujeres aborígenes, sino también sobre toda la sociedad prehispánica en su conjunto.

\section{Hombres y mujeres juntos, pero no revueltos}

El trabajo protagoniza uno de los ámbitos de la vida social donde mejor se expresan las sin- 
gularidades históricas que definen a una sociedad y a un periodo histórico. Desde un punto de vista general, el trabajo es el conjunto de tareas que se realizan para satisfacer las necesidades humanas y reproducir unas determinadas relaciones sociales que son específicas de cada cultura, comunidad, etc. Algunas de esas tareas están asignadas en función del sexo y suponen una distinta valoración social, económica y simbólica que, además, repercute en la dimensión temporal del trabajo, con una concreción diferente del tiempo de trabajo/tiempo liberado para hombres y mujeres.

Las fuentes etnohistóricas revelan cómo algunas de las tareas cotidianas de los antiguos canarios estaban reguladas según el sexo de las personas. Esta división sexual del trabajo ordenaba, según estos relatos, las asimetrías más sustanciales que se articulaban en la organización social del trabajo, si bien no era la única, puesto que, en otros casos, los documentos describen cómo intervenían otras razones vinculadas al estatus social, la especialización laboral, y la ubicación geográfica de los asentamientos aborígenes (Velasco y Alberto, 2005; Santana et al., 2011-2012). Si bien muchos de estos relatos están mediatizados por la visión androcéntrica de los europeos de la época, la separación por sexos descrita en estos textos coincide con la información etnográfica acerca de la sociedad tradicional canaria que, por norma general, vincula a las mujeres con el ámbito más doméstico de la vida cotidiana (González Pérez, 2008; Monzón Perdomo, 2012).

En una contribución reciente se analizaron diferentes marcadores esqueléticos de actividad física con el objetivo de analizar las asimetrías sexuales en el patrón cotidiano de actividad física de la población aborigen de Gran Canaria (Santana et al., 2015). Los resultados de este estudio indicaron que el patrón de actividad física masculino se asociaba fundamentalmente con los movimientos articulados desde el hombro, la flexo-extensión del codo y la pronosupinación del brazo. Estos movimientos son realizados en el contexto de actividades de gran esfuerzo físico o cuando se desarrollan acciones que implican la articulación de los músculos más vigorosos de la extremidad superior. Aunque es imposible asociar estos gestos con trabajos específicos, sí que se pueden interpretar en el contexto de las actividades laborales conocidas para los antiguos canarios, como la fabricación de casas, cuevas habitacionales, graneros y otras estructuras al aire libre, la ma- nipulación de la madera, la explotación de los recursos líticos, etc. La robustez de algunos de estos marcadores esqueléticos también puede asociarse con los trabajos asociados a la agricultura donde, según los textos etnohistóricos, los hombres protagonizaban actividades que implicaban un esfuerzo físico significativo, como el acondicionamiento de las parcelas de cultivo, la preparación del suelo y la roturación del terreno. Según estos textos, "La manera de cultivar la tierra para su sementera era juntar veinte y más canarios, cada uno con una casporra de cinco o seis palmos, y junto a la porra tenían un diente en que metian un cuerno de cabra. Yendo uno otro surcaban la tierra (...)", (Abreu Galindo, [1632] 1977:160), “Ayudáuase unos a otros a sembrar, quen acauando uno hauía de ayudar luego a su vecino, hasta que se acabaze la sementera" (López de Ulloa, en Morales Padrón, 2008:315).

Los restos pertenecientes a hombres aborígenes también reflejaban un patrón de movilidad más elevado que el registrado en las mujeres. Esta diferencia sugiere que el grupo masculino ejercía un papel más significativo en los trabajos y actividades que precisaban de un mayor número e intensidad de desplazamientos. Es probable que este patrón de movilidad sea resultado del pastoreo del ganado, el transporte de las materias primas necesarias para los trabajos artesanales, o el traslado de las producciones agrícolas desde los campos de cultivo hasta los asentamientos y graneros. No hay que olvidar que la ausencia de animales de carga en la Gran Canaria prehispánica determinó un sistema de transporte basado en la tracción humana (Santana y Moreno, 2015), una particularidad que seguramente también explica por qué los marcadores de actividad física de la extremidad superior presentan en los hombres un desarrollo más importante que en las mujeres.

La aparente responsabilidad de los hombres en muchos de los trabajos habituales de los antiguos canarios no implica la falta de protagonismo de las mujeres en otras actividades igual de importantes para la reproducción social. Los marcadores esqueléticos de esfuerzo físico de las mujeres exhiben un patrón de actividad donde destacan los movimientos de la flexión y pronosupinación del brazo, en combinación con movimientos de la mano. Ciertos trabajos vinculados al mundo de la agricultura que las fuentes etnohistóricas asocian preferentemente con las mujeres, como sembrar, cosechar y 
procesar lo producido con molinos de mano, concuerdan con estos marcadores y, además, se distancian significativamente del perfil observado para los hombres aborígenes: " $i$ después las mujeres los deshacían i allanaban la tierra (...)" "molíanlas en unos molinitos pequeños que andaban a la manos las mujeres de una piedra negra mojeteada y fuerte (...)" (Sedeño (S. XVII) en Morales Padrón, 2008:372) "cuando estaban en sazón las sementeras, las mujeres las cogían llevando un zurrón colgado al cuello, y cogían solamente la espiga, que después apaleaban o pisaban con los pies, y con las manos lo aventaban (...)" (Abreu Galindo, [1632] 1977:160). También destacan entre las mujeres los marcadores asociados con los movimientos de fineza de la mano, aquellos necesarios para elaborar artesanías donde no sólo es necesaria la fuerza, sino también la precisión. Este patrón enlaza adecuadamente con las descripciones de los relatos etnohistóricos, que comentan como "tenían mujeres dedicadas para sastres, como para hacer loça de que usaban que eran tallas como tinajuelas para agua. Hacianlas a mano y almagrábanlas $i$ estando enjutas las bruñian con piedras lisas i tomaba lustre bueno y durable".

Un estudio previo ya había señalado que algunos esqueletos aborígenes exhibían ciertos marcadores de actividad física compatibles con procesos de trabajo que requerían experiencia y destreza técnica (Delgado et al., 2002; Delgado, 2009). En esta contribución se analizaron más de 500 cráneos procedentes de la colección antropológica de El Museo Canario, y en tan sólo cuatro de ellos, todos de sexo femenino, se hallaron piezas dentales con desgastes extra-masticatorios asociados a la utilización de los dientes como herramientas en la fabricación de cueros y tejidos vegetales. El porcentaje de individuos afectados por estos desgastes $(0,7 \%$ del total y $2,16 \%$ de las mujeres), ha sido interpretado como evidencia de que algunas mujeres eran especialistas dedicadas al trabajo de las fibras vegetales y la elaboración de pieles. Lo cierto es que muchos de los productos fabricados en cuero y textiles vegetales conservados en la actualidad demuestran un elevado conocimiento en la elaboración de estas artesanías. De igual forma, los textos etnohistóricos también llaman la atención sobre el carácter especializado de estos procesos de trabajo, señalando que "las mujeres hasian esteras de juncos majados y curados para cubrirse, y para colchón como está dicho queste y no otro hera su ordinario exercisio" (López de Ulloa en Morales Padrón, 2008:315).

El conjunto de estas evidencias define un panorama general donde las labores de mayor envergadura y exigencia física eran realizadas por los hombres. Entre tanto, las mujeres fueron protagonistas de aquellas actividades donde tenían especial importancia los gestos asociados a las manos. En ambos casos, los marcadores esqueléticos de esfuerzo físico describen el impacto de hábitos cotidianos realizados con intensidad y durante un periodo prolongado en el tiempo. Lejos de responder a coyunturas esporádicas, estos perfiles derivan de condiciones de actividad física recurrentes y asimétricas según el sexo, que reflejan en cierta medida, una división sexual del trabajo (Santana et al., 2015).

Al principio de este texto se decía que, según nuestra hipótesis, existía un sistema de género desigual basado en la dominación masculina. Si bien la existencia de una división sexual del trabajo no conduce irremediablemente a la explotación y/o subordinación de las mujeres, sí que puede llegar a originar y a perpetuar ciertas disimetrías sociales. Es aquí donde el acceso a lo socialmente producido puede demostrar la distinta valoración del estatus del trabajo entre hombres y mujeres, pues a pesar de que todas las actividades laborales son necesarias para la perpetuación de la sociedad, no siempre son consideradas de igual forma actuando como un mecanismo de explotación social del sistema patriarcal.

\section{Lo comido por lo servido...}

La arqueología también permite investigar el acceso de hombres y mujeres a lo socialmente producido (Delgado, 2009). Un ejemplo es la disponibilidad y alcance a los diferentes recursos alimenticios que genera una sociedad según el sexo y la posición social de las personas. En el caso de la población aborigen de Gran Canaria, varios estudios bioarqueológicos señalan un acceso asimétrico a determinados productos alimenticios según el sexo de las personas, repercutiendo en una alimentación de peor calidad para las mujeres. Las evidencias arqueológicas indican que la subsistencia de los antiguos canarios se sustentaba en una economía agrícola excedentaria que $a$ priori, fue capaz de asegurar la perpetuación de su modo de vida hasta la conquista castella- 
na de la isla (Morales et al., 2014). El impacto del consumo de los productos agrícolas en la población aborigen se observa nítidamente en algunos marcadores dietéticos, como la caries dental, con un $17.3 \%$ de las piezas dentales afectadas para todo el conjunto de la población (Delgado, 2009). Este porcentaje tan elevado es resultado de una dieta rica en carbohidratos que, en el caso de los antiguos canarios, derivaba de un importante consumo de gofio (harina fina de cereal tostado) mezclado con leche de cabra. Estos alimentos, si bien suficientes para subsistir, son escasos en ciertos nutrientes que son necesarios para tener una dieta saludable y, de hecho, los aborígenes la completaban con productos cárnicos, marinos y de recolección. No obstante, los datos bioantropológicos sugieren que el acceso a estos otros recursos alimenticios estaba condicionado especialmente por el sexo de las personas. El porcentaje de caries dental, las pérdidas dentales antemortem, y los porcentajes de oligoelementos en el tejido óseo, etc. (Velasco, 1999; Delgado, 2009), señalan que la alimentación de las mujeres estaba configurada por un porcentaje más elevado de productos agrícolas y una ingesta menor de productos cárnicos procedentes de la cabaña ganadera. En cambio, el estado nutricional de los hombres revela un aporte más importante de proteínas animales, como se observa, por ejemplo, en una mayor prevalencia de cálculo dental y en un porcentaje inferior de caries y otras patologías asociadas. Estos datos se ven reforzados por la incidencia de la osteoporosis no senil, una patología que afectó a casi un $20 \%$ de la población aborigen de Gran Canaria. Esta enfermedad implica una disminución de la densidad del tejido óseo antes de la vejez como consecuencia de procesos de malnutrición o de una dieta poco saludable. La incidencia de esta patología ha sido interpretada como reflejo de una nutrición hipoproteica basada fundamentalmente en la ingesta de productos agrícolas (Velasco, 1999). También en este caso, cuando se analizan los porcentajes de osteoporosis no senil según el sexo se advierte un valor significativamente superior en las mujeres, quizás como resultado de un acceso más restringido a los productos cárnicos.

El conjunto de estas asimetrías refleja un acceso diferencial a lo producido socialmente. Si bien no tenemos otras evidencias arqueológicas que permitan investigar desigualdades sexuales en el acceso o disfrute de otro tipo de bienes, lo cierto es que las diferencias en la alimentación están poniendo de relieve la distinta valoración social que tiene el trabajo femenino. A pesar de que el papel de las mujeres como fuerza de trabajo tuvo que ser tan importante como el de los hombres para la subsistencia los antiguos canarios, el sistema patriarcal dominante, en cualesquiera de las instituciones en que se sostuvo, determinó un valor diferente para el trabajo de hombres y mujeres y, en consecuencia, la explotación de un grupo por otro.

\section{El que quiera lapas...}

Un caso excepcional en la organización del trabajo y en el acceso a lo producido lo supone la explotación de los recursos marinos. Junto con la agricultura y la ganadería, la pesca y el marisqueo fueron la principal fuente de alimento de los antiguos canarios (Rodríguez Santana, 1996; Velasco, 1999; Delgado, 2009). Las conchas de lapas y burgaos (Patella aspera, Patella candei crenata, Patella piperata, Ossilinus atratus, etc.) y los restos de pescado (Sparisoma cretense, Serranus atricauda, Dentex dentex, Trachynotus ovatus, Sardina pilchardus, etc.), aparecen con abundancia en los poblados de la costa (Rodríguez Santana, 1996; Rodríguez Santana et al., 2008; Alberto et al., 2018), y su consumo también se observa en los esqueletos de la población sepultada en el litoral, con una prevalencia menor de caries y cálculo dental gracias al efecto anticariógeno de estos alimentos (Delgado, 2009).

La importancia de esta práctica económica se refleja también en la presencia de exostosis del canal auditivo en un buen número de los esqueletos que proceden de las necrópolis situadas en la costa de la isla (Velasco et al., 2000). Este marcador consiste en una anomalía ósea que se crea en el oído como respuesta al contacto cotidiano con el agua fría del mar, y hoy en día afecta frecuentemente a surfistas, buceadores y mariscadores (Fig. 3). En un estudio realizado con 323 cráneos (179 masculinos, 129 femeninos y 15 alofisos), un 40,21\% de los individuos procedentes de la costa mostraban esta anomalía (39 de 97), mientras que únicamente un $0,88 \%$ de los originarios del interior presentaban esta enfermedad (2 de 226). En los cráneos de la costa afectados por exostosis auditiva no se registraron variaciones significativas según el sexo de los esqueletos $(n=27 / 179,15,08 \%$ en hombres; $n=14 / 129$, 
$10,85 \%$ en mujeres), lo que indica que no hubo diferencias en el desempeño de las actividades relacionadas con el medio marino. De hecho, es muy probable que tanto hombres como mujeres participaran por igual en la pesca y el marisqueo (Velasco et al., 2000).

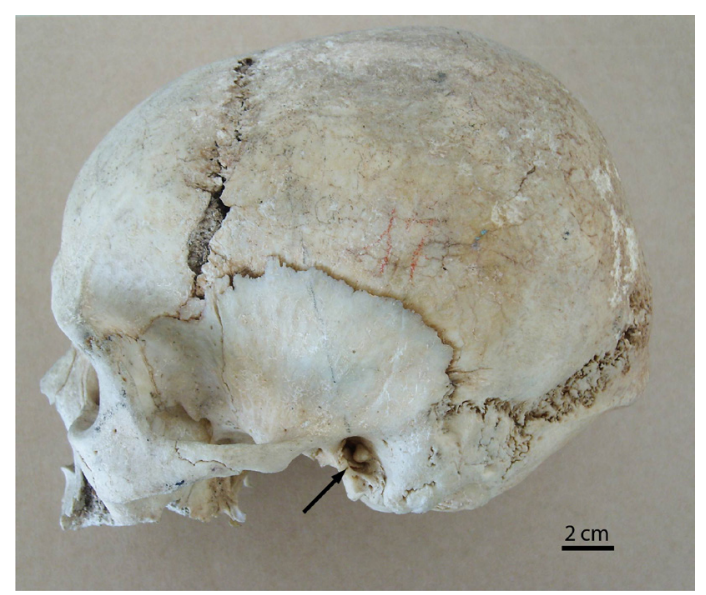

Figura 3. Cráneo masculino con exostosis en el canal auditivo (flecha). Necrópolis de El Agujero-La Guancha en Gáldar.

En ese caso, el análisis biantropológico viene a confirmar la información recogida en las fuentes etnohistóricas, donde se comenta que "Quando reconocían en la costa del mar hauer cardume de pescado, se arrojaban a nado hombres $i$ mujeres $i$ muchachos, $i$ la rodeaban $i$ hacian venir cerca de tierra, $i$ con esteras de juncos poniendo piedras por la parte vaxa sacaban gran cantidad de sardina i liças" (Gómes Scudero, en Morales Padrón, 2008:441).

\section{Andamana, Arminda y un matrimonio de conveniencia}

Los textos etnohistóricos recogen el nombre de muchos aborígenes que fueron protagonistas del proceso de contacto y conquista castellana de la isla. La inmensa mayoría de estas referencias hacen mención a hombres que pertenecían al grupo social dirigente o que participaron activamente en la defensa de la isla. Muchos de estos personajes fueron idealizados según los cánones varoniles de la sociedad europea de inicios de la Edad Moderna, por lo que no es extraño que en estos documentos los hombres canarios aparezcan como honorables, valientes y diestros en el arte de la guerra. Cabría preguntarse si estas descripciones derivan del talante real de los varones isleños o, siendo precisos, de los miembros masculinos de la élite indígena o, por el contrario, supone una exageración orientada a mitificar al enemigo haciendo más extraordinaria la victoria castellana.

La historia de algunas mujeres que tuvieron un protagonismo especial entre los antiguos canarios también llamó la atención de los escritores que narraron el encuentro de europeos y aborígenes (Rodríguez, 2000). El relato más interesante lo constituye el mito de Andamana y Gumidafe, la pareja que según estos textos unificó bajo su mando toda la isla de Gran Canaria y dio origen al clan de los Guanartemes. En el siglo XIV, la isla estaba dividida en varias demarcaciones independientes como Agáldar, Telde, Agüimes, Arguineguín, Arucas, entre otras. En Agáldar, según estas fuentes, había una mujer llamada Andamana o Atidamana que era muy respetada gracias a su virtuosismo y su capacidad de liderazgo. Andamana se unió a Gumidafe, un guerrero de Agáldar, y juntos se hicieron con el dominio de toda la isla: "En el término de Gáldar, donde era lo mejor de la isla, había una doncella, a quien por sus buenas partes todos respetaban. Y tenía en sus palabras tanta fuerza, que movía a lo que ella quería a los naturales, y así en sus pendencias luego ella los componía y ponía en paz. Pero al cabo de algunos años, como los canarios eran enemigos que las mujeres se entremetiesen en negocios varoniles, considerando que era poquedad suya apaciguar sus debates y pendencias a instancia y persuasión de una mujer, no se curaron de hacer lo que la doncella Atidamana les persuadía, y no dejaban de proseguir en sus pasiones. Atidamana, 
como entendió el poco respeto que le iban teniendo, y que les daba poco por sus ruegos, sintióse por afrentada de haber sin ocasión perdido el crédito; $y$, como tenía vivo entendimiento, procuró casarse y tratólo con un capitán de las cuadrillas que se decía Gumidafe... por parecerle más valiente y de más discreción que los demás. El capitán Gumidafe túvelo en buena suerte; $y$, efectuándose el casamiento, hicieron guerra a todos los demás capitanes, a los cuales sujetó y puso toda la isla bajo su dominio y mando" (Abreu Galindo, [1632] 1977:171). Cuando murieron, legaron el poder a su hijo Artemi Semidán, quién se hizo célebre por la victoria sobre los normandos de Jean de Bethencourt en la costa de Arguineguín a principios del siglo XV. Este matrimonio sería además el origen de la dinastía de los guanartemes que gobernaron Telde y Agáldar, las dos grandes demarcaciones políticas en las que se dividía la isla hasta la conquista castellana a finales del siglo XV.

Este mito ha sido utilizado por algunos investigadores para señalar la matrilinealidad en la trasmisión del poder en la sociedad indígena, y una personificación del héroe mítico, encarnado por Andamana, que traduce el paso de una sociedad tribal a una jefatura única y centralizada (Martín de Gúzman, 1984; Pérez Saavedra, 1997; Onrubia, 2003). Los textos etnohistóricos también aportan otros argumentos que sustentan la hipótesis de la matrilinealidad en la transmisión del poder. Es el caso de Arminda, hija del Guanarteme de Agáldar Guayasu Semidán El Bueno, y último rey reconocido por todos los canarios. Cuando muere Semidán El Bueno, el poder lo asume provisionalmente su hermano o sobrino, Tenesor Semidán (Fernando Guanarteme), tío o primo de Arminda. El poder religioso también lo detentaba un tío de la niña, el faycán de Telde Guanache Semidán, hermano de la mujer de Guayasu Semidán (Rodríguez, 2000; Morales Padrón, 2008). Si bien los castellanos consideraban a Tenesor Semidán como el último guanarteme, los canarios sólo lo reconocían como el " $t u$ tor" de Arminda. Al mismo tiempo, Bentejuí o Bentago, el guanarteme de Telde y uno de los líderes de la resistencia aborigen, quería concertar su matrimonio con Arminda, por aquel entonces bajo su custodia, para hacerse con el poder legítimo de la isla (Morales Padrón, 2008:364). Sin embargo, Bentejuí y los suyos terminan rindiéndose a los castellanos tras el sitio en la fortaleza de Ansite, y junto al faycán de Telde, se lanzan al vacío desde los riscos de Tirajana al grito de Atis Tirma. Justamente, la conquista de Gran Canaria finaliza cuando los canarios entregan a Arminda a los castellanos. Según los textos etnohistóricos, "Los canarios salieron de Tirajana acompañando a su señora. Traíanla en unas andas senlada en ombros de quatro hidalgos de cavellos rubios; traís vestido un zamarrón que la cubría toda, echo de gamuza, i la cabeza traía tocada o aderezada a uso de las españolas... Venían junto a las andas un poco hacia atrás a los lados los dos tios faycanes, $i$ delante $i$ atrás muchos de los idalgos que traían cavellos largos" (Sedeño (S. XVII) en Morales Padrón, 1978: 364). Estos relatos han servido para proponer que los guanartemes y su linaje mantenían una endogamia que favorecía los matrimonios entre primos, y donde las mujeres como transmisoras de los derechos del linaje eran utilizadas según los intereses de los hombres para el ejercicio del poder (Rodríguez, 2000). Este escenario pone de manifiesto la ausencia de mujeres en las instituciones de poder, donde el guanarteme y el faycán, ambos hombres, ejercían como responsables de la autoridad política y religiosa respectivamente.

El sistema matrilineal que se sugiere para la clase dirigente no puede extrapolarse directamente al resto de la población aborigen, de la que apenas tenemos información etnohistórica (Rodríguez, 2000; Santana, 2011). De hecho, estos relatos permiten distinguir un comportamiento diferente para los otros grupos sociales, donde también tenía cabida el ejercicio de la dominación social a través del control del parentesco (Rodríguez, 2000; Onrubia, 2003). Es el caso de los pasajes donde se menciona que los villanos, el grueso de la población indígena, estaban obligados a ofrecer al guanarteme la hospitalidad de lecho cuando éste pasaba la noche en alguna aldea fuera de su residencia habitual: "Quando el rey hacia viaje alguna parte, en los lugares onde se aloxaba el dueño de el hospedaxe le ofrecía la mujer o su hija, lo que más bien apeteciesse, i si lo admitía, que pocas veces lo rehusaba, los hijos que aquellas pariessen toda su vida de alli en adelante eran nobles" (Gómes Scudero en Morales Padrón, 2008:436). Otra práctica semejante, relatada también en los textos etnohistóricos, consistía en el ejercicio del derecho de prima nocte, por el cual los guanartemes y los nobles tenían la autoridad para acostarse con las mujeres re- 
cién casadas en la primera noche de su casamiento, donde además "si quedaba preñada del cavallero, el hijo que nacía era cavallero; e si no, los fijos de su marido era comunes. E para ver si quedaba preñada, es esposo no llegaba a ella fasta saberlo por cierto, por vía de la purgación" (Bernáldez en Morales Padrón, 2008:515-516). Estas costumbres, de ser ciertas, contradicen la transmisión materna de la filiación, e introducen otros elementos de discusión, como los mecanismos de ascenso social, la dominación de un grupo sobre otro, y la violencia institucional contra la mujer, que se percibe en prácticas como la hospitalidad de lecho (Rodríguez, 2000; Onrubia, 2003).

\section{En su casa el enemigo}

Un estudio bioantropologico sobre los cráneos de la población de Guayadeque, un barranco del sureste de Gran Canaria con numerosas cuevas funerarias, revela la alta incidencia de traumatismos craneales inducidos por violencia entre los antiguos canarios (Delgado et al., 2018). El porcentaje de individuos afectados por este tipo de heridas $(27,4 \%)$, sitúa esta sociedad entre las poblaciones arqueológicas más violentas conocidas hasta la fecha concordando, además, con el patrón de violencia característico de sociedades estratificadas antiguas. El tipo de lesiones, su frecuencia y distribución sugiere, asimismo, combates normalizados como consecuencia de violencia inter-personal y no como resultado de guerras intergrupales (Delgado et al., 2018).
Los resultados de esta investigación aportan diferencias estadísticas significativas entre hombres y mujeres que son compatibles con asimetrías sexuales en el ejercicio de la violencia y en las causas sociales que explican los traumatismos craneales en esta población (Delgado et al., 2018:8). En concreto, los individuos masculinos presentan un 33,3\% $(n=60 / 182)$ de traumas por un $19,2 \%(n=25 / 130)$ en el conjunto femenino (Fig. 4). Además, mientras la frecuencia de traumatismos es similar entre los distintos grupos de edad en el grupo masculino, en las mujeres fue significativamente superior en el tramo de edad de 25-35 años, decreciendo con el aumento de los años. Delgado y colaboradores señalan que la distribución de las lesiones craneales en las mujeres tenía una prevalencia similar en los parietales y el frontal, mientras que en los hombres la frecuencia en el hueso frontal es significativamente superior $(57,4 \%, n=62 / 108)$, con respecto a los parietales $(27,8 \%, n=30 / 108)$. Estos investigadores interpretan estas evidencias como una manifestación del protagonismo de los hombres en los enfrentamientos violentos. Esta interpretación concuerda con los relatos de las fuentes etnohistóricas que describen la presencia de guerreros masculinos en el grupo dominante, y de cómo solían combatir entre ellos con el propósito de acaparar mayor prestigio social (Morales Padrón, 2008). Estas asimetrías sexuales se visibilizan también en el hecho de que hay una ausencia absoluta de traumas letales en mujeres, una condición que, sin embargo, está presente en un $2.7 \%$ de los individuos masculinos examinados en este trabajo $(n=5 / 182)$.

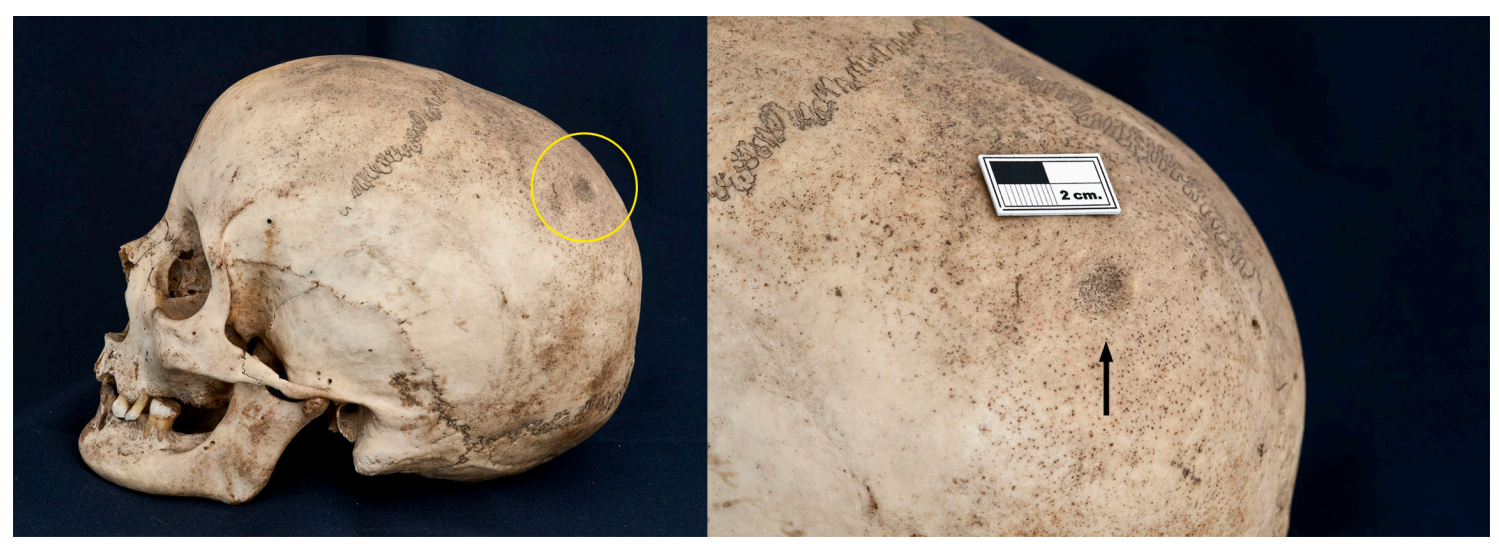

Figura 4. Fractura deprimida antemortem en el parietal izquierdo de un cráneo femenino de Guayadeque (Archivo El Museo Canario). 
Una de las cuestiones que recalcan Delgado y colaboradores, es que el patrón de distribución de las heridas y la ausencia de muertes asociadas a los traumatismos craneales en el grupo femenino, pueden estar indicando que la violencia ejercida contra las mujeres tuvo lugar en el contexto doméstico y/o familiar. Esta hipótesis no solo considera la violencia de genero entre los antiguos canarios, sino que también plantea la posibilidad de una violencia ejercida por las mujeres contra las mujeres. Para argumentar esta hipótesis señalan varios ejemplos de sociedades donde se registra violencia femenina dirigida hacia las mujeres que son incorporadas a las unidades domesticas en el contexto de sociedades patrilocales (Jankowiak et al., 2005; Martin y Harrod, 2014), como así se sugiere para el caso de los antiguos canarios (Morales Padron, 2008), y que cuyo proposito es la obediencia y el establecimiento de relaciones de poder entre mujeres que habitan el mismo espacio doméstico (Delgado et al., 2018).

\section{Imaginando la abundancia}

La supervivencia de los canarios estaba irremediablemente sujeta a la productividad de su agricultura y ganadería, en un contexto autárquico, donde era imprescindible asegurar la sostenibilidad del sistema económico y la pervivencia del modo de vida. Hay que recordar que, en el estado actual de la investigación, no se tienen evidencias del contacto de los indígenas canarios con otros territorios, tanto insulares como continentales (Velasco, 2015). Esto significa que las posibles crisis de supervivencia debieron ser resueltas mediante estrategias endógenas donde no cabía la posibilidad de recurrir a otros territorios fuera de Gran Canaria. Ciertamente, una realidad tan dependiente de la capacidad reproductora de una isla con un contexto ecológico sensible debió, a todas luces, influir de forma decisiva en la ideología de los antiguos canarios. Así lo corroboran los relatos etnohistóricos que mencionan la realización de importantes celebraciones religiosas dedicadas a la fertilidad (Tejera Gaspar, 2001). Estos ritos eran dirigidos por el faycan, el líder religioso de la comunidad, que iba acompañado por un grupo de mujeres jóvenes llamadas maguadas, que eran sostenidas por los guayres y guanartemes: "Tenian también doncellas que guardaban castidad, viuian en cuevas i casas de tierra" (Sedeño (S. XVII), en Morales Padrón2008:373). "Estas maguas no salían de su monasterio sino era para pedir a Dios buenos tiempos; si alguna quería salirse fuera hauía se ser para casar" (Gomez Scudero, en Morales Padrón, 2008:436).

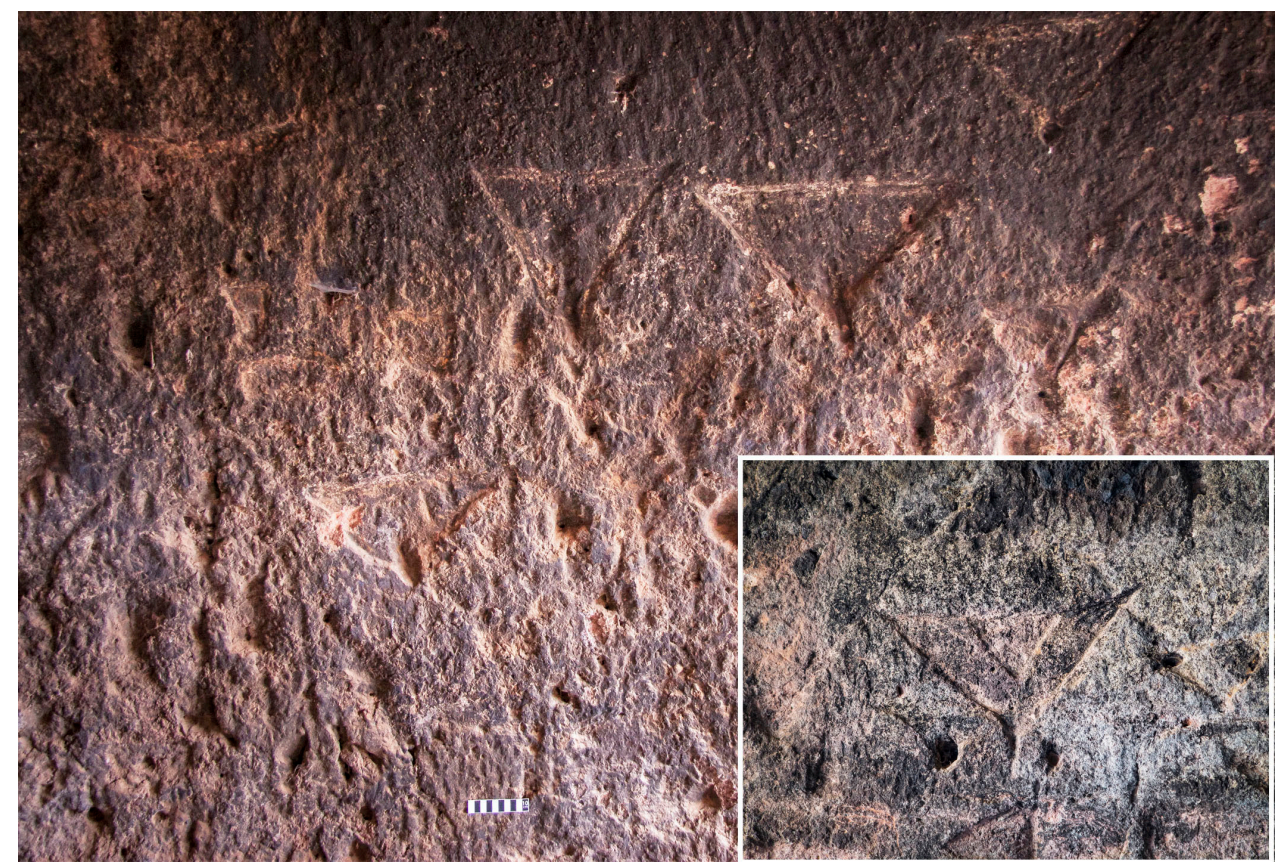

Figura 5. Perspectiva y detalle de uno de los paneles de grabados pubiformes de la cueva artificial de Los Candiles, Artenara (Ernesto Martín Rodríguez). 
La relación de las mujeres con la fertilidad también parece advertirse en algunas cuevas artificiales donde los antiguos canarios grabaron numerosos triángulos invertidos. Estos triángulos representan la vulva de la mujer y han sido interpretados como símbolos asociados al culto de la fertilidad (Cuenca y Rivero, 1992-1994; López et al., 2009). Las cuevas donde estas manifestaciones se encuentran debieron funcionar como espacios especializados de carácter religioso, como en Risco Caído, Cuevas de Lezcano, Cueva Caballero y Cueva Candiles (Fig. 5). Estas últimas dos cuevas se sitúan en un lugar muy relevante dentro de la Caldera de Tejeda, orientadas al Roque Bentayga, en cuya zona superior se ubica un almogaren, uno de los espacios que tradicionalmente se han vinculado a los santuarios donde según las fuentes etnohistóricas los faycanes y las maguadas realizaban sus ritos y ofrendas religiosas asociadas con la fertilidad.

En el registro arqueológico de los asentamientos indígenas también se advierte un culto similar, pero con un carácter más doméstico. En concreto, se trata de un conjunto muy variado de figurillas de barro cocido, popularmente conocidas como "ídolos", que suelen aparecer asociadas a espacios domésticos como en Cueva Pintada, Arucas, La Fortaleza, E1 Tejar, Los Barros, entre otros. Estas figuras incluyen representaciones antropomórficas, zoomórficas, y en algunos casos, hibridaciones de estas dos categorías (Onrubia et al., 2000). En un gran número de ejemplos, estas figurillas representan mujeres con los atributos sexuales muy visibles, incluso aparecen algunos ídolos encarnando mujeres embarazadas o con ciertos atributos corporales sobredimensionados (Onrubia et al., 2000). La figura más destacada es el llamado "ídolo de Tara", una pieza que representa una mujer sentada con las piernas cruzadas y los brazos en jarra (Fig. 6). Las extremidades de esta figura aparecen muy gruesas personificando a una mujer obesa. En contraste, muestra un cuello alargado y delgado que sostiene una pequeña cabeza con los rasgos faciales escasamente representados, lo que sugiere que el propósito era destacar determinadas regiones corporales como el sexo, el vientre y las extremidades. Es probable que estos ídolos representen pautas o reglas de figuración que reflejan una metáfora de las creencias asociadas a la fertilidad como, por ejemplo, la costumbre de sobrealimentar a las mujeres antes del matrimonio como mecanismo para asegurar su fecundidad.

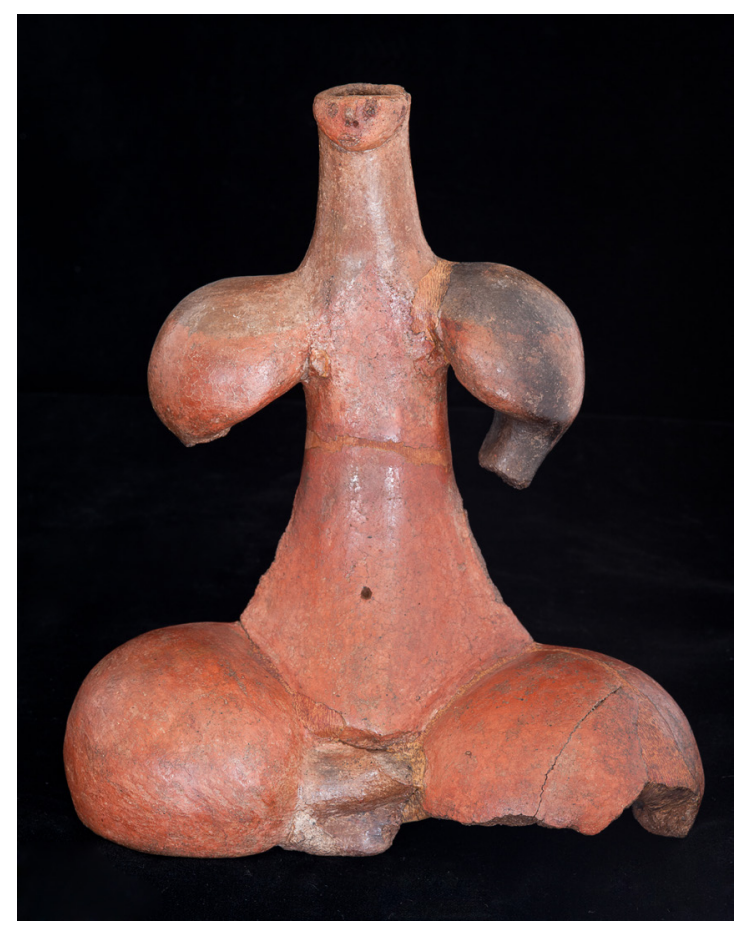

Figura 6. Ídolo de Tara (Archivo El Museo Canario). Constituye la pieza más emblemática de la cultura material de los aborígenes de Gran Canaria. 


\section{Madre no hay más que UNA}

El control ejercido socialmente sobre la reproducción biológica, así como el significado socioeconómico de la procreación y de la descendencia, están en el origen y desarrollo de las asimetrías sociales basadas en el sexo (Colomer et al., 1994; Vila y Ruiz, 2001; Sanahuja, 2002). La reproducción biológica humana es, en sí misma, un trabajo específico, una producción básica sin la cual no existiría la sociedad (Castro et al., 1998). Esta capacidad establece una primera división del trabajo en función del sexo, que a priori no implica disimetrías sociales si no se potencian mediante prácticas sociales destinadas a tal fin (Comas, 1995; Escoriza y Castro, 2011). Sin embargo, la especialización y responsabilidad de las mujeres en la reproducción biológica y los trabajos de cuidados asociados, ha obstaculizado históricamente el acceso de las mujeres a los recursos generados por la sociedad en condiciones de igualdad con los hombres.

En las sociedades agrícolas antiguas, como la prehispánica de Gran Canaria, la principal fuerza de trabajo y medio de producción eran las personas. Como la creación de nuevas personas es un proceso que incumbe principalmente a la capacidad reproductora de las mujeres, muchas sociedades desarrollaron mecanismos para controlar la sexualidad femenina mediante reglas matrimoniales y otras estrategias sociales, asegurando el control de la reproducción en función de unos intereses que no siempre coincidían con los de las mujeres (Bourdieu 2000; Vila y Ruiz, 2001; Sanahuja, 2002). En los textos etnohistóricos sobre los antiguos canarios se describe que las mujeres prehispánicas eran engordadas antes de su matrimonio y parecer más fértiles a los ojos de los hombres. En ellos se comenta que las muchachas estaban recluidas durante un mes durante el cual bebían gran cantidad de leche con gofio y otros alimentos para engordar: "Más antes que con ellos duerman, las engordan tanto con leche, que su piel se carga como hacen los higos; porque no tienen a la flaca por tan buena como a la gorda, pues dicen que se le alarga el vientre para hacer hijos grandes" (Zurara [1452-1453] 1998:332-353); “i había casas o cuebas onde acistían, $i$ estaban gordas $i$ regalalas. Savían coser i tostar i salían para casarlas quando las pedían, i sólo con la voluntad eran ya casadas, $i$ hacen un convite $i$ vailes se celebraba el desposorio" (Gómes Scudero, en Morales Padrón, 2008:433-434) Este engorde prematrimonial ayudaría a acelerar la menarquía en las más jóvenes y aseguraría la fertilidad en las mayores, consiguiendo un porcentaje adecuado de grasa en el cuerpo capaz de estabilizar la regla. Una vez embarazadas, este engorde garantizaría el buen curso de la gestación, la lactancia y reforzaría el sistema inmunológico (Velasco, 2009). Este tipo de prácticas irían encaminadas fundamentalmente a controlar y asegurar la reproducción de las personas, la fertilidad de la propia sociedad y son, además, una expresión de la dominación masculina sobre las mujeres.

El éxito de esta práctica puede rastrearse en los marcadores de estrés episódico presentes en los esqueletos aborígenes, como las hipoplasias del esmalte dental o de líneas de Harris en los huesos largos, cuya incidencia en esta población revela pocos problemas de malnutrición durante la infancia (Velasco, 1999; Delgado, 2009; Velasco, 2009). En todo caso, los principales desequilibrios pueden asociarse a cambios en la alimentación por el paso de la lactancia materna a otro tipo de dieta. Así que el engorde de estas mujeres aparentemente cumplió el propósito de evitar carencias nutricionales en los niños durante su gestación y crecimiento, y eventualmente durante los periodos de carestía (Velasco, 2009). Otra cosa son las repercusiones físicas y psicológicas que este engorde prematrimonial pudo ocasionar entre las mujeres.

Ellas también fueron las únicas víctimas de los peligros físicos derivados de la reproducción biológica. En los escasos estudios demográficos afrontados hasta el momento, se observa una mortalidad femenina superior a la de los hombres entre los 20 y 35 años de edad (Velasco, 2009; Santana et al., 20112012). Este periodo coincide plenamente con la etapa fértil de las mujeres y su incidencia deriva, muy posiblemente, de los peligros derivados del parto, el posparto y los embarazos continuos. Como ejemplo está el caso de una sepultura de la necrópolis de Juan Primo que contenía una mujer embarazada con un feto casi a término de 8 - 9 meses de gestación (Fig. 7). Aunque es imposible determinar a ciencia cierta la causa de la muerte, no es de extrañar que su fallecimiento esté relacionado con una complicación durante la última fase del embarazo (Santana et al., en revisión). 


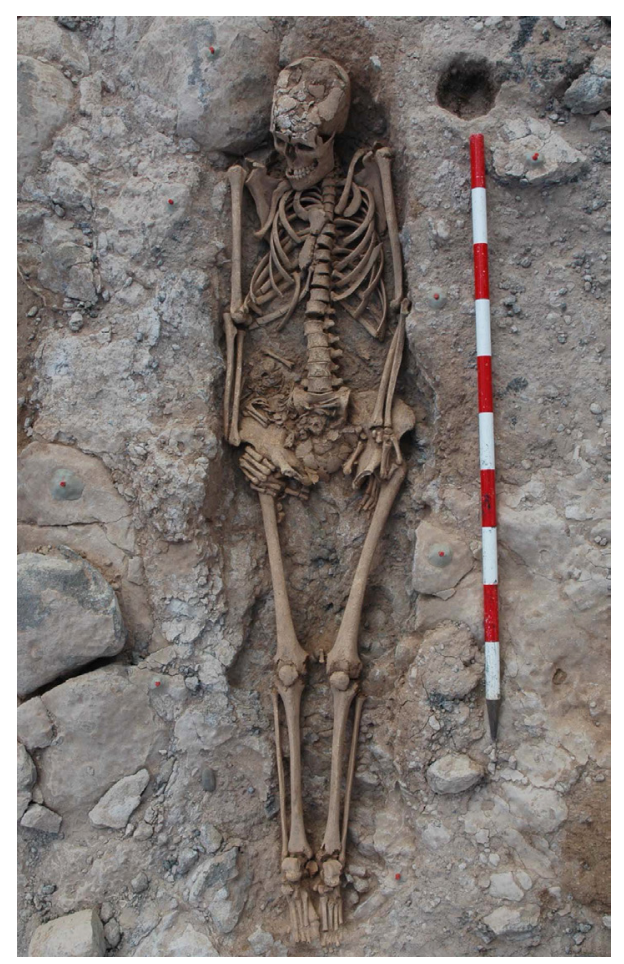

Figura 7. Sepultura primaria en fosa de mujer embarazada con feto en región abdominal (Tibicena, Arqueología y Patrimonio).

La existencia de un sistema socioeconómico basado en la agricultura excedentaria permitió a los antiguos canarios mantener un contingente poblacional importante, al menos durante los últimos siglos de ocupación aborigen antes de la conquista castellana (Velasco, 1999; Delgado, 2009; Morales, 2010). Así lo sugiere la gran cantidad de asentamientos repartidos por toda la geografía insular y las estimaciones poblaciones recogidas en las fuentes etnohistóricas $(\approx 25.000$ personas) (Onrubia, 2003). Sin embargo, el equilibrio entre capacidad de subsistencia y población pudo haber sido inestable en determinadas coyunturas, ya como resultado de un aumento demográfico desmedido, malas cosechas, o decisiones desafortunadas. En otros territorios estos desequilibrios son solucionados frecuentemente con la expansión a otros lugares ocupados por otros grupos, incluso cuando no son bienvenidos. El mejor ejemplo lo representa la emigración de miles de jóvenes africanos hacia países menos empobrecidos de África y Europa, que se ven expulsados de sus países por la falta de oportunidades, la guerra, la hambruna, las dictaduras, su orientación sexual, etc., ejerciendo su derecho a la vida y a la supervivencia. Pero en el caso de la Gran Canaria prehispánica, un aumento demográfico desproporcionado o una crisis de subsistencia importante, únicamente pudo haber sido solventado mediante estrategias endógenas, ya que por lo que se sabe, los antiguos canarios no tenían contacto con otras islas o con el continente africano (Velasco, 2015). Una de las soluciones para controlar el aumento poblacional pudo ser, por ejemplo, el control de los matrimonios como relatan las fuentes etnohistóricas: "Heran hombres poco sensuales, quen esto tenían su castigo quando cometían este delito, y de 50 años habia en todo lo más del común que no conocía muger" (López de Ulloa [1646] en Morales Padrón, 2008:316).

Otra estrategia de control demográfico pudo haber sido el infanticidio activo. Se conservan citas etnohistóricas que relatan cómo los canarios se vieron obligados a controlar su población por medio de esta estrategia radical. Según esta información, años antes de que comenzara la conquista de la isla se había producido un desfase entre la producción de alimentos, el tamaño poblacional y el sistema socio-político aborigen. Para contrarrestar estas circunstancias adversas los canarios optaron por el infanticidio, una estrategia que permitía solventar la situación a corto plazo y, al mismo tiempo, seguir sosteniendo una estructura socio-política con desigualdades en 
el acceso a lo producido socialmente: "Pocos años antes de que la isla de Canaria fuese conquistada, bien por fecunda influencia del cielo o por vivir la gente con salud por espacio de muchos años, seguían naciendo sin que los acompañasen en igual cantidad las defunciones. De este modo creció la gente en tanta cantidad que ya no bastaban las cosechas para su manutención, y empezaron a padecer carestía, a tal punto, que, obligados por la necesidad, para que no perecieran todos, hicieron una ley inhumana, que matasen a todos los hijos después del primer parto (...)" (Torriani [c. 1592] 1978:115-116). Algunos cronistas llegan a especificar que las niñas fueron las principales víctimas de este episodio, ya que así no sólo se limitaba el número de personas nacidas, sino además, la cantidad de futuras reproductoras: "Y viendo como iban en crecimiento, y los mantenimientos les faltaban y no cogían frutos que bastasen a su sustento, por no vivir en estrechura, entrando en consulta y congregación que llaman sabor, acordaron e hicieron un estatuto que se matasen a todas las hembras que de alli en adelante naciesen, con tal de que no fuesen los primeros partos que las mujeres hacian (porque los tales vientres reservaban para su conservación), y asi supliesen los frutos que la tierra produjese, y no les faltasen, como había sucedido los años atrás (...)" (Abreu Galindo, [1632] 1997:107). No obstante, es probable que la discrepancia del relato en el texto de Abreu Galindo con respecto a lo escrito por Leonardo Torriani sea en realidad una interpretación del primero. Por lo que, en cualquier caso, se debe ser precavido a la hora de asociar únicamente este episodio de infanticidio con las niñas.

En el yacimiento de El Portichuelo-Cendro, un asentamiento troglodita situado en Telde, se han hallado concentraciones inusuales de más de 30 recién nacidos en un contexto habitacional datado por métodos radiocarbónicos entre el 900 y el 1200 d.C. Estas evidencias, si bien no pueden asociarse cronológicamente con el episodio narrado en los textos etnohistóricos, han sido interpretadas como resultado de prácticas de infanticidio realizadas por los antiguos canarios (Cuenca et al., 1996). No obstante, a falta de estudios especializados sobre estas evidencias, y teniendo en cuenta que se ubican en un contexto de habitación junto a los desechos domésticos, no se puede descartar otras interpretaciones más bien vinculadas al tra- tamiento funerario (Velasco, 2009). Según esta otra perspectiva, los restos infantiles de Cendro-El Portichuelo reflejarían la ausencia de una práctica funeraria dirigida a las personas fallecidas durante su primera etapa de vida $\mathrm{o}$, al menos, un tratamiento que difiere sustancialmente de las normas sepulcrales aplicadas a la mayor parte de la población (Velasco, 2009; Campagne, 2010; Santana et al., 2010).

\section{Así en la vida como en la muerte}

La investigación arqueológica ha permitido establecer que en la organización del espacio funerario el sexo fue un atributo personal tenido en cuenta, quizás como representación de las relaciones de género indígena. Un ejemplo lo supone la composición demográfica de la necrópolis tumular de El Agujero-La Guancha, en Gáldar. En este cementerio hay un $70 \%$ de hombres y un $30 \%$ de mujeres, a diferencia de otros espacios funerarios como Juan Primo o Maspalomas, donde esta distribución se presenta al $50 \%$ aproximadamente (Santana et al., 2011-2012). Lo interesante de El Agujero-La Guancha es que se trata de una necrópolis muy particular en el contexto de las prácticas funerarias aborígenes. Está formada por varios túmulos de morfología troncocónica donde destaca el Túmulo de la Guancha, la construcción funeraria más sobresaliente de los antiguos canarios y la que acoge más personas. El carácter singular de esta necrópolis ha sido interpretado como reflejo del alto estatus social que las personas allí sepultadas tendrían, llegando incluso a ser considerada como el cementerio de la nobleza indígena (Martín de Guzmán, 1984). Teniendo en cuenta estas particularidades, se puede aventurar que en El Agujero-La Guancha la distribución asimétrica de sexos fue más significativa por tratarse de la élite indígena, que como ya se ha sugerido, es probable que tuviera un sistema de género diferente al de la mayor parte de la población (Rodríguez, 2000; Santana et al. 2011-2012).

En las sepulturas del yacimiento de Los Caserones, en La Aldea de San Nicolás, se advierte como el espacio preeminente o central era siempre ocupado por un individuo de sexo masculino, al contrario que las mujeres, que eran ubicabas en lugares periféricos. Este comportamiento también refleja asimetrías sexuales que pueden ser resultado de un sistema 
de género basado en la dominación masculina $\mathrm{o}$, lo que es lo mismo, de una sociedad regida por el patriarcado (Rodríguez, 2000).

Esta práctica no es óbice para que en ciertas circunstancias las mujeres también ocupen lugares destacados en la organización de los espacios funerarios. Un ejemplo se encuentra en la necrópolis de Lomo Maspalomas, un extenso cementerio compuesto principalmente por inhumaciones individuales en cista y fosas. En este caso, algunas mujeres fueron sepultadas en el interior de cistas de piedras y en lugares preeminentes, que articulaban la organización de otras sepulturas que acogían tanto a hombres como a mujeres. Es probable que estas personas, a pesar de pertenecer al sexo femenino, atesoraran un estatus diferente que destacaba con respecto a la consideración social de la población sepultada en fosas, quizás como resultado de una posición más privilegiada en la organización social de los antiguos canarios.

El patrón de actividad física de los aborígenes y su relación con los soportes funerarios también nos aporta información sobre el papel de las mujeres canarias (Santana et al., 2011-2012; Santana et al., 2015). Cuando los marcadores esqueléticos de esfuerzo físico se analizaron en función de dónde habían sido sepultadas las personas (fosas, cistas y cuevas), los resultados mostraron que las mujeres inhumadas en cista exhibían un perfil de actividad física particularizado con respecto a las depositadas en fosa y en cueva. Lo mismo ocurría con aquellas que aparecían en fosa, con una expresión en sus marcadores esqueléticos también diferenciado con respecto a las mujeres que fueron ubicadas en cista y cueva. Esto significa que dentro del grupo de fosas y cista, había mujeres con un patrón de actividad física que sobresalía con respecto al patrón general y que, al mismo tiempo, se diferenciaba entre sí. Los resultados también plantean que, junto a razones como las relaciones de parentesco y el estatus social, la organización del espacio sepulcral de las mujeres estaba sujeto en cierta medida al trabajo que realizaban en su vida cotidiana que, a tenor de los datos, debió alcanzar cierto grado de dedicación y especialización. Lo mismo ocurre con los hombres, con un perfil de actividad física más específico o especializado en aquellas personas que fueron sepultadas en cistas (Santana, 2011).

\section{Cierre}

La investigación sobre el papel de las mujeres aborígenes constituye una de las líneas más prometedoras de la arqueología insular. Las evidencias ponen de manifiesto asimetrías sociales basadas en el sexo que se expresaban en múltiples ámbitos de la realidad social. Los datos arqueológicos sugieren que estas diferencias entre hombres y mujeres reflejan un sistema social patriarcal que se sustentaba en una relación de explotación y dominación social que beneficiaba a los varones. No obstante, quedan muchas incógnitas por resolver y muchos problemas que abordar. Si bien las evidencias presentadas en este texto y en la historiografía referenciada permiten tener un panorama inicial de cómo fue la historia de las mujeres aborígenes, no es menos cierto que estas aportaciones y reflexiones adolecen de una temporalidad y territorialidad específica, una singularidad más allá de la generalidad con la que acostumbramos ver a la sociedad prehispánica de Gran Canaria. Aun así, lo que vamos sabiendo sobre las mujeres aborígenes no deja de ser un éxito de la investigación arqueológica y, en especial, de las mujeres y hombres de la profesión que revirtieron la tendencia secular de estudiar la sociedad de los hombres, recuperando del anonimato a aquellas mujeres y niñas que también hicieron posible la cultura de los antiguos canarios.

\section{Agradecimientos}

Quisiera agradecer la invitación de Gustavo A. Trujillo Yánez para participar como conferenciante en las XII Jornadas de Patrimonio Cultural de Teror de 2016. Este texto es resultado de intervención en este evento y de las reflexiones individuales y colectivas que surgieron antes, durante y después de las jornadas con muchos de los arqueólogos que investigan en la isla de Gran Canaria. Igualmente, debo agradecer los excelentes comentarios realizados por Julie Campagne que han mejorado considerablemente el resultado final de este texto. Mis agradecimientos a El Museo Canario, Tibicena: Arqueología y Patrimonio, y a Ernesto Martín por ceder sus fotografías para este artículo. Finalmente, quisiera agradecer a los dos revisores anónimos sus enriquecedores comentarios sobre el manuscrito. 


\section{Bibliografía}

Abreu Galindo, J. [1632] (1977): Historia de la conquista de las siete islas de Canaria. Introducción y notas de A. Cioranescu. Goya Ediciones, Santa Cruz de Tenerife.

Alberto Barroso, V.; Mendoza Medina, F.; Suárez Medina, I.; Moreno Benítez, M.; Alamón, M. (2018): Estudio zooarqueológico de La Restinga (Gran Canaria). Datos para la definición de un modelo productivo. Actas del XXII Coloquio de Historia Canario-Americano, Las Palmas de Gran Canaria: 1-17.

Aznar Vallejo, E., (1983): La Integración de las Islas Canarias en la Corona de Castilla (1478-1526). Universidad de Sevilla-Universidad de La Laguna, Secretariado de Publicaciones, Madrid.

Baucells Mesa, S. (2004): Crónicas, historias, relaciones y otros relatos: Las fuentes narrativas del proceso de interacción cultural entre aborígenes canarios y europeos (siglos XV a XVII). Fundación Caja Rural de Canarias, Las Palmas de Gran Canaria.

Bourdieu, P. (2000): La dominación masculina. Anagrama, Colección Argumentos, Barcelona.

Campagne, J. (2010): Los otros muertos: los individuos no adultos en el registro funerario aborigen de Gran Canaria. Diploma de Estudios Avanzados. Departamento de Ciencias Históricas. Universidad de Las Palmas de Gran Canaria, Inédito.

Castro, P.; Gili Suriñach, S.; Lull, V.; Micó Perez, R.; Rihuete Herrada, C.; Risch, R.; Sanahuja Yll, M.E. (1998): Teoría de la Producción de la Vida Social. Un Análisis de los Mecanismos de Explotación en el Sudeste Peninsular (c. 3000-1550 CAL ANE). Boletín de Antropología Americana, 33: 24-77.

Colomer, E.; Gili, S.; González Marcen, P.; Monton, S.; Picazo, M.; Rihuete, C.; Ruiz, M.; Sanahuja Yll, M.E.; Tenas, M. (1994): Género y Arqueología: Las Mujeres en la Prehistoria. Arqrítica, 6: 5-8.

Comas D’Argemir, D. (1995): Trabajo, Género, Cultura. La construcción de desigualdades entre hombres y mujeres. Institut Catalá d'Antropologia, Icaria Editorial, Barcelona.

Cuenca Sanabria, J.; Rivero, G. (1992-1994): La Cueva de los Candiles y el Santuario del Risco Chapín. El Museo Canario, 49: 59-99.

—; Betancor, A.; Rivero, G. (1996): La práctica del infanticidio femenino como método de control de la natalidad entre los aborígenes canarios: las evidencias arqueológicas en Cendro, Telde, Gran Canaria. El Museo Canario, 51: 103-180.

Delgado Darias, T. (2009): La historia en los dientes. Una aproximación a la prehistoria de Gran Canaria desde la antropología dental. Ediciones Cabildo de Gran Canaria, Las Palmas de Gran Canaria.

-; Arnay De La Rosa, M.; Velasco Vázquez, J.; Y González Reimers, E. (2002): Pequeñas huellas del pasado: análisis del modelo de microestriación dentaria de la población prehistórica de Gran Canaria. El Museo Canario, 57: 9-28.

-; Alberto Barroso, V., Velasco Vázquez, J. (2018). Violence in paradise: Cranial trauma in the prehispanic population of Gran Canaria (Canary Islands): American Journal of Physical Anthropolology, early view:1-14. https://doi.org/10.1002/ajpa.23400

Escoriza Mateu, T.; Castro Martínez P.V. (2011): ¿Tal como éramos? Reconstrucciones, ficciones y diseños en la interpretación de las representaciones figurativas de las sociedades ágrafas. Revista atlántica-mediterránea de prehistoria y arqueología social, 13: 97-118.

Fregel, R.; Pestano, J.; Arnay, M.; Cabrera, V.M.; Larruga, J.M.; González, A.M. (2009): The maternal aborigine colonization of La Palma (Canary Islands). European Journal of Human Genetics 17: 1314-1324.

González Marrero, M.C.; Rodríguez Rodríguez, A. (1998): La mirada del otro: de cómo los europeos percibieron la vestimenta de los antiguos canarios. Actas del XII Coloquio de Historia Canario-Americana, Las Palmas de Gran Canaria: 675-696.

-; Rodríguez Rodríguez, A. (2006): «Etno» historias y arqueologías de la periferia. El caso de la reconstrucción del pasado preeuropeo del Archipiélago Canario. Treballs d'etnoarqueologia, 6: 109-120.

González Pérez, T. (2008): Mujeres rurales, la infinita presencia. El Pajar: Cuaderno de Etnografía Canaria, 25: 21-27.

Jankowiak, W.; Sudakov, M.; Wilreker, B. C. (2005): Co-wife conflict and co-operation. Ethnology, 44: 81-98.

López Peña F.; Cuenca Sanabria J.; Guillén Medina J. (2009): El triángulo púbico en la prehistoria de Gran Canaria: nuevos hallazgos arqueológicos. Actas del XV Coloquio de Historia Canario-Americana, Las Palmas de Gran Canaria: 2243-2264.

Maca Meyer, N.; Arnay, M.; Rando, J.C.; Flores, C.; González, A.M.; Cabrera, V.M.; Larruga, J.M. (2004): European Journal of Human Genetics, 12: 155-162 
Martin, D.; Harrod, R.; Fields, M. (2010): Beaten down and worked to the bone: Bioarchaeological investigations of women and violence in the ancient southwest. Landscape of Violence, 1, 1, 3. http:// scholarworks.umass.edu/lov/vol1/iss $1 / 3$

Martín de Guzmán, C. (1984): Las culturas prehistóricas de Gran Canaria. Ediciones Cabildo de Gran Canaria, Las Palmas de Gran Canaria.

Monzón Perdomo, M.E. (2012): Género y vida cotidiana. Oficios femeninos en las ciudades canarias en el Antiguo Régimen. En La vida de cada día: rituales, costumbres rutinas cotidianas en la España Moderna (Franco Rubio, G.A. Ed.), Asoc. Cult. Al Mudayna, Madrid: 273-298.

Morales Padrón, F. (2008): Canarias: Crónicas de su Conquista. Ediciones del Cabildo Insular de Gran Canaria, Las Palmas de Gran Canaria.

Morales Mateos, J. 2010: El Uso de las Plantas en la Prehistoria de Gran Canaria: Alimentación, Agricultura y Ecología. Monografía Cueva Pintada 1. Ediciones Cabildo de Gran Canaria, Las Palmas de Gran Canaria.

-; Rodríguez Rodríguez, A.; González Marrero, M.C.; Martín Rodríguez, E.; Henríquez-Valido, P.; Del Pino Curbelo, M. (2014): The archaeobotany of long-term crop storage in northwest African communal granaries: a case study from pre-Hispanic Gran Canaria (CAL. AD 1000-1500). Vegetation history and archaeobotany, 23(6): 789-804.

Morales, J.; Rodriguez, A.; Henriquez, P. (2017): Agricultura y recolección vegetal en la arqueología prehispánica de las Islas Canarias (siglos XI-XV d.C.): la contribución de los estudios carpológicos. En Miscelánea en homenaje a Lydia Zapata Peña (1965-2015) (Fernández-Eraso, J.; Mujika-Alustiza, J.A.; Arrizabalaga-Valbuena, A. Eds.). Universidad del País Vasco/Euskal Herriko Unibertsitatea, Vitoria: $189-218$.

Onrubia Pintado J. (2003): La isla de los Guanartemes. Territorio, sociedad y poder en la gran canaria indigena (siglos XIV-XV). Ediciones Cabildo de Gran Canaria, Las Palmas de Gran Canaria.

—; Fleitas, A. R.; Santana, C.; Sagasti, J. S. (2000): Ídolos canarios. Catálogo de terracotas prehispánicas de Gran Canaria. El Museo Canario, Las Palmas de Gran Canaria.

Pérez Saavedra, F. (1997) [1982]: La mujer en la sociedad indígena de Canarias. Centro de la Cultura Popular Canaria, Santa Cruz de Tenerife.

Rodríguez Rodríguez, A. (2000): Mujer y poder en la prehistoria de Gran Canaria. Vegueta, 5:47-58.

- (2006): Cuestiones de sexo en Arqueología. El pasado pre-europeo de las islas desde una perspectiva de género. El Pajar. Cuaderno de etnografia canaria, 21: 107-118.

Rodríguez Santana, C.G. (1996): La pesca entre los canarios, guanches y auaritas. Ediciones Cabildo de Gran Canaria, Santa Cruz de Tenerife.

-; Alberto Barroso, V.; Rodríguez Rodríguez, A.; Galindo Rodríguez, A: (2008): Escamas y cuernos: a propósito de asociaciones insólitas en el yacimiento de Lomo de Los Melones (Telde, Gran Canaria). En Archéologie du poisson. 30 ans d'archéo-ichtyologie au CNRS (Desse, J. ; Desse-Berset, N., Eds.), APDCA, Antibes: 1-14.

Sanahuja Yll, M.E. (2002): Cuerpos Sexuados. Objetos y Prehistoria. Ediciones Catedra-Universidad de Valencia, Barcelona.

Santana Cabrera, J. (2009-2010): Marcadores óseos de actividad física en la población aborigen de Gáldar (Siglos XI-XV). Vegueta, 11: 101-122.

- (2011): El trabajo fosilizado: patrón cotidiano de actividad física y organización social del trabajo en la Gran Canaria prehispánica. Tesis doctoral. Universidad de Las Palmas de Gran Canaria.

—; Mendoza Medina, F.; Suárez Medina, I.; Moreno Benítez, M. (2010): Niños en la memoria: el depósito funerario del Barranquillo del Cabezo. El Museo Canario, 65: 9-30.

-; Velasco-Vázquez J.; Rodríguez-Rodríguez A. (2011-2012): Patrón cotidiano de actividad física y organización social del trabajo en la Gran Canaria prehispánica (siglos XI-XV): la aportación de los marcadores óseos de actividad física. Tabona: Revista de prehistoria y de arqueología, 19: 125-163.

-; Moreno Benítez, M. (2015): Movilidad y Adaptación Biomecánica: Una aproximación a la relación entre territorio y propiedades geométricas de la extremidad inferior en la población prehispánica de Gran Canaria. Revista Cientifica y Tecnológica UPSE, 1(3): 1-7.

-; Velasco-Vázquez J.; Rodríguez-Rodríguez A. (2015): Entheseal changes and sexual division of labor in a North-African population: The case of the pre-Hispanic period of the Gran Canaria Island (11th-15th c. CE). HOMO 66(2): 118-138. 
—;Alamón Núñez, M.; Alberto Barroso, V. Delgado Darias, D. (en revision): Exploring the risks accompanying child-bearing in the aboriginal society on Gran Canaria (Canary Islands, 13th-15th Cal. AD): death of a pregnant woman during her third trimester. HOMO.

Torriani, L. (1978): Descripción e Historia del Reino de las Islas Canarias antes Afortunadas, con el parecer de sus fortificaciones. Goya Ediciones, Santa Cruz de Tenerife.

Velasco Vázquez, J. (1999): Canarios. Economía y dieta de una sociedad Prehistórica. Ediciones del Cabildo de Gran Canaria, Las Palmas de Gran Canaria.

-; Alberto Barroso, V. (2005): Donde habita la Historia. La población prehispánica de Agüimes y su territorio. Ayuntamiento de Agüimes, Las Palmas de Gran Canaria.

—; Betancor Rodríguez, A.; Arnay de La Rosa, M.; González Reimers, E. (2000): Auricular exostoses in the prehistoric population of Gran Canaria. American Journal of Physical Anthropology, 112(1): 49-55.

-; Delgado, T.; González, E.; Sánchez, S.; Ruíz, T. (2001): De una sociedad igualitaria a la complejidad de las normas sociales: prevalencia de caries en la población prehistórica de la Necrópolis de La Lajura (La Frontera, El Hierro). Tabona: Revista de prehistoria y de arqueología, 10: 213-245.

- (2009): Nacer para morir. Algunas consideraciones sobre las estrategias de reproducción de los antiguos canarios. Nacimiento, matrimonio y muerte en Canarias. VI Jornadas de Patrimonio Cultural de Teror (Suárez Grimón, V.; Trujillo Yánez, G.A.; Domínguez Talavera, O. Eds.), Anroart, Santa Cruz de Tenerife: $215-260$.

— (2015): Más allá del horizonte: una "perspectiva humana" del poblamiento de Canarias. Orígenes. Enfoques interdisciplinares sobre el poblamiento indígena de Canarias (Farrujia de La Rosa, J. Ed.), Thesaurus Arqueología, Ediciones Idea, Santa Cruz de Tenerife: 25-89.

Vila, A.; Ruiz Del Olmo, G. (2001): Información Etnológica y Análisis de la Reproducción Social. El Caso Yámana. Revista Española de Antropología Americana, 31: 275-291.

Zurara, G. E. [1452-1453] (1998): Crónica del descubrimiento y conquista de Guinea. Zurara. Crónica del descubrimiento y conquista de Guinea (Hernández González, M. y Delgado Luis, J.A. eds.), Excmo. Ayuntamiento del Puerto de la Cruz y Excmo. Ayuntamiento de la Villa de La Orotava, Santa Cruz de Tenerife: 41-65. 